\title{
Separation and Recovery of Gold, Platinum and Palladium by a Trioctylamine Liquid Membrane ${ }^{\dagger}$
}

\author{
Jianshun Fu, Shigeto Nakamura and Kenichi AKIBa \\ Institute for Advanced Materials Processing, Tohoku University, Aoba, Sendai 980-77, Japan
}

\begin{abstract}
The carrier-mediated transport of gold(III), platinum(IV) and palladium(II) through a supported liquid membrane (SLM) has been investigated by the use of trioctylamine (TOA) as a mobile carrier. The transport behavior of precious metals greatly depended on the carrier concentration. At a low TOA concentration, Au(III) was preferentially transported across an SLM from the $\mathrm{HCl}$ feed solution to the $\mathrm{HClO}_{4}$ product solution. The transport of $\mathrm{Pt}(\mathrm{IV})$ and Pd(II) was enhanced with increasing carrier concentration. The separation factor of $\mathrm{Au}(\mathrm{III})$ over Pt(IV) and Pd(II) was improved with increasing concentration of $\mathrm{HCl}$ in the feed solution.
\end{abstract}

Keywords Carrier-mediated transport, supported liquid membrane, trioctylamine, precious metal

The utility of carrier-containing membranes has been proposed for the selective recovery of metal ions from dilute solutions. ${ }^{1}$ The transport behavior of metal species in aqueous solutions has been widely investigated and some interesting processes have been reported concerning the recovery of metals. ${ }^{2-6}$ However, the separation and concentration of precious metals by supported liquid membranes (SLM) have been rather limited in a few cases, because effective extractants employed as mobile carriers in some cases suffer from major problems, such as slow extraction rates and difficulties in stripping. ${ }^{7}$ Furthermore, precious metals tend to precipitate on the interface in some extraction processes, which may cause practical problems in liquidmembrane transport. 8,9

In previous studies ${ }^{9-11}$ trioctylamine (TOA) was found to exhibit good properties as a mobile carrier for the transport of $\mathrm{Au}(\mathrm{III}), \mathrm{Pt}(\mathrm{IV})$ and $\mathrm{Pd}(\mathrm{II})$ at relatively high transport rates. The transport of those individual precious metals across a TOA-SLM has been performed by the use of some suitable stripping solutions.

This paper discusses the possibility of the separation and recovery of precious metals from an $\mathrm{HCl}$ solution in a TOA liquid-membrane system.

\section{Experimental}

\section{Materials}

Trioctylamine (TOA; Wako Pure Chemical Ind.) was

\footnotetext{
$\dagger$ Presented at the ITAS 94, August 23-28, 1994, HakodateSapporo, Japan.

J.F.: On study leave from Chemical Engineering Research Center, East China University of Chemical Technology, Shanghai 200237, P. R. China.
}

diluted with kerosene. A sample solution containing gold(III), platinum(IV) and palladium(II) was prepared by diluting the standard solution of each metal $(1000 \mathrm{ppm})$ in $1 \mathrm{M}\left(=\mathrm{mol} \mathrm{dm}^{-3}\right) \mathrm{HCl}$ (Wako). Other chemicals used here were of guaranteed reagent grade.

\section{Liquid-liquid extraction}

An aqueous solution $\left(10 \mathrm{~cm}^{3}\right)$ initially containing $1.27 \times 10^{-4} \mathrm{M} \mathrm{Au}(\mathrm{III}), 2.56 \times 10^{-4} \mathrm{M} \mathrm{Pt}(\mathrm{IV})$ and $2.35 \times$ $10^{-4} \mathrm{M} \operatorname{Pd}(\mathrm{II})$ was contacted with an equal volume of a TOA-kerosene solution modified with $20 \%(\mathrm{v} / \mathrm{v})$ 1octanol for $5 \mathrm{~min}$ at $25^{\circ} \mathrm{C}$. After phase separation by centrifugation, the concentrations of metals in the aqueous phase were measured by inductively coupled plasma atomic emission spectrometry (ICP-AES). The metal concentration in the organic phase was obtained by mass balance.

\section{Transport of metals}

An apparatus comprising inner and outer polypropylene compartments was used for transport experiments. ${ }^{12}$ A polytetrafluoroethylene membrane with an average pore size of $0.45 \mu \mathrm{m}$, a porosity of $74 \%$ and a thickness of $80 \mu \mathrm{m}$ was attached to the bottom of the inner compartment and impregnated with a TOAkerosene solution modified with $20 \%(\mathrm{v} / \mathrm{v}) 1$-octanol in favor of stripping and a stable liquid membrane.9,10 An $\mathrm{HCl}$ feed solution $\left(100 \mathrm{~cm}^{3}\right)$ containing $\mathrm{Au}(\mathrm{III}), \mathrm{Pt}(\mathrm{IV})$ and $\mathrm{Pd}(\mathrm{II})$ was placed in the outer compartment; an equal volume of a stripping product solution was placed in the inner compartment. The two solutions separated by the SLM were shaken at 120 strokes per $\min (\mathrm{spm})$ at $25^{\circ} \mathrm{C}$. The feed and product solutions were periodically sampled and the metal concentrations were determined by ICP-AES. 


\section{Results and Discussion}

\section{Liquid-liquid extraction}

An extractant, trioctylamine (TOA; $\mathrm{R}_{3} \mathrm{~N}$ ), is protonated in contact with an acid (HX) solution, which serves as an ion exchanger for anionic metal complexes; ${ }^{13,14}$ the extraction processes can be represented as

$$
\mathrm{R}_{3} \mathrm{~N}_{\text {org }}+\mathrm{HX}_{\mathrm{aq}} \rightleftharpoons \mathrm{R}_{3} \mathrm{NH}^{+} \mathrm{X}_{\text {org }}^{-}
$$

and

$$
\mathrm{MX}_{m, \mathrm{aq}}^{n-}+n \mathrm{R}_{3} \mathrm{NH}^{+} \mathrm{X}_{\mathrm{org}}^{-} \rightleftharpoons\left(\mathrm{R}_{3} \mathrm{NH}^{+}\right)_{n} \mathrm{MX}_{m, \mathrm{org}}^{-}+n \mathrm{X}_{\mathrm{aq}}^{-} \text {. }
$$

In the extraction of $\mathrm{Au}(\mathrm{III}), \mathrm{Pt}(\mathrm{IV})$ and $\mathrm{Pd}(\mathrm{II})$ from the $\mathrm{HCl}$ solution, the $\mathrm{MX}_{\bar{m}}^{-}$aq species appears corresponding to $\mathrm{AuCl}_{4}{ }^{-}, \mathrm{PtCl}_{6}{ }^{2-}$ and $\mathrm{PdCl}_{4}{ }^{2-}$, respectively.

The distribution ratios $(D)$ of $\mathrm{Au}(\mathrm{III}), \mathrm{Pt}(\mathrm{IV})$ and Pd(II) with $10^{-3} \mathrm{M}$ TOA in $20 \%$ (v/v) 1-octanol-kerosene are plotted against the $\mathrm{HCl}$ concentration in Fig. 1. Gold(III) was effectively extracted, even by low concentrations of TOA in comparison with $\mathrm{Pt}(\mathrm{IV})$ and Pd(II). The $D$ value for $A u(I I I)$ first varied inversely with the $\mathrm{HCl}$ concentration, and then further varied directly with the $\mathrm{HCl}$ concentration. In a low-concentration region of $\mathrm{HCl}$ the slope of the plot was about -0.9 , being close to -1 , as expected from Eq. (2). An increase in the extractability of $\mathrm{Au}(\mathrm{III})$ at high $\mathrm{HCl}$ concentrations may be attributable to a salting-out effect accompanying a reduction in the activity of water. The $D$ values of $P t(I V)$ and $P d(I I)$ decreased with increasing $\mathrm{HCl}$ concentration, and only little extraction occurred at high $\mathrm{HCl}$ concentrations. Plots for $\mathrm{Pd}(\mathrm{II})$ yielded a rather gentle slope of about -1.5 , compared with that expected from Eq. (2); this deviation may have been due to an increase in the ion strength. The extraction sequence was found to be $\mathrm{Au}(\mathrm{III}) \gg \mathrm{Pd}(\mathrm{II})>\mathrm{Pt}(\mathrm{IV})$.

The effect of the TOA concentration on the $D$ values is illustrated in Fig. 2. The $D$ values for individual metals increased along with the TOA concentration, and the extraction became quantitative at a high TOA concentration. These plots give individually curved lines having slopes of about 1 for $\mathrm{Au}$ (III), and about 2 for both $\mathrm{Pt}(\mathrm{IV})$ and $\mathrm{Pd}(\mathrm{II})$ in the region of low TOA concentration. Large increases in the distribution ratios along with the TOA concentration may be attributable to a decrease in the $\mathrm{HCl}$ concentration in the aqueous phase via the extraction of $\mathrm{HCl}$ with TOA.

The high extraction power of TOA would provide a large driving force for the transport of precious metals across the liquid membrane from the feed solution, though it may accompany some difficulties in metal stripping. Perchloric acid, having a very strong affinity for TOA, was found to be efficient for the stripping of $\mathrm{Pt}(\mathrm{IV})$ and $\mathrm{Pd}(\mathrm{II})$, even from an organic solution with a high TOA concentration, while Au(III) could be stripped only at a low TOA concentration..$^{\dot{9}-11}$

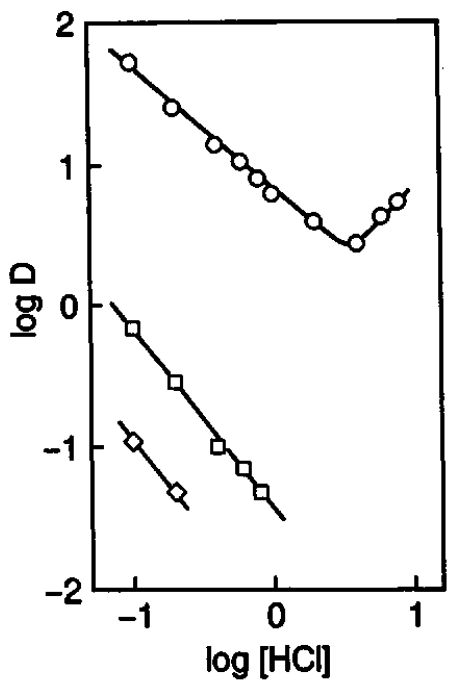

Fig. 1 Effect of the $\mathrm{HCl}$ concentration on the extraction of precious metals. Organic phase: $10^{-3} \mathrm{M}$ TOA and $20 \%(\mathrm{v} / \mathrm{v})$ 1-octanol in kerosene. $\operatorname{Au}(\mathrm{III})(\mathrm{O}), \operatorname{Pt}(\mathrm{IV})(\diamond), \operatorname{Pd}(\mathrm{II})(\square)$.

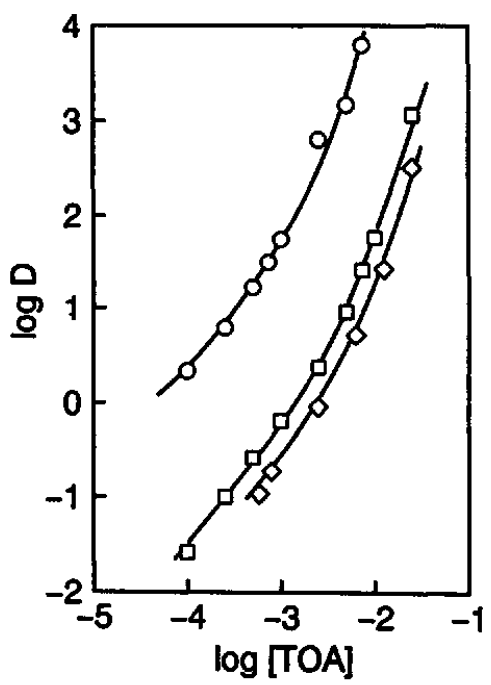

Fig. 2 Effect of the TOA concentration on the extraction of precious metals. Aqueous phase, $0.1 \mathrm{M} \mathrm{HCl}$; organic phase, TOA and 20\%(v/v) 1-octanol in kerosene. $\mathrm{Au}(\mathrm{III})(\mathrm{O})$, $\operatorname{Pt}(\mathrm{IV})(\diamond), \operatorname{Pd}(\mathrm{II})(\square)$.

\section{Transport of $A u(I I I), P t(I V)$ and $P d(I I)$}

On the basis of the extraction behavior of precious metals, membrane transport was performed by employing TOA as a mobile carrier and perchloric acid as a stripping agent. Figure 3 represents the time-dependent fractions of precious metals in the feed and product solutions for transport across an SLM containing $10^{-3} \mathrm{M}$ TOA. The fractions of precious metals on the feed side decreased along with the shaking time, and those on the product side almost symmetrically increased. After a 


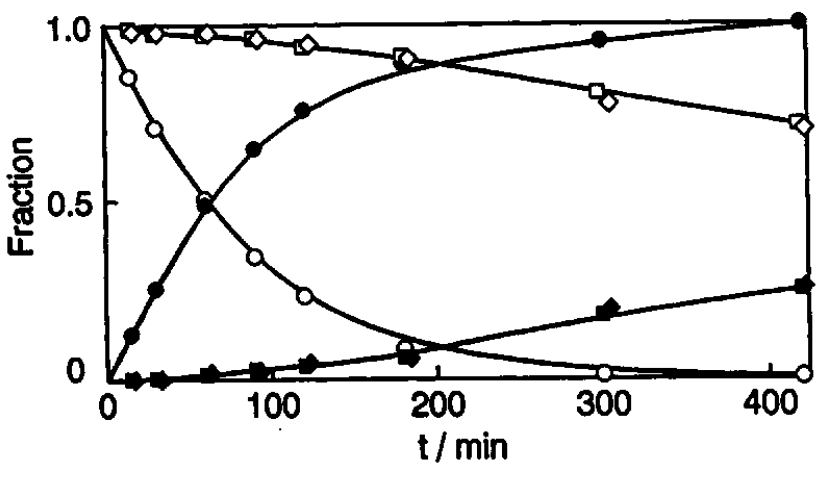

Fig. 3 Transport of precious metals through an SLM containing $10^{-3} \mathrm{M}$ TOA and $20 \%(\mathrm{v} / \mathrm{v})$ 1-octanol. Feed, $0.1 \mathrm{M}$ $\mathrm{HCl}$; product, $1 \mathrm{M} \mathrm{HClO}$. $\mathrm{Au}(\mathrm{III})(\mathrm{O}, \diamond), \mathrm{Pt}(\mathrm{IV})(\diamond, \diamond)$, $\operatorname{Pd}(\mathrm{II})(\square, \square)$. Open, feed; closed, product.

$7 \mathrm{~h}$ run, $\mathrm{Au}(\mathrm{III})$ was nearly quantitatively transported from the feed solution of $0.1 \mathrm{M} \mathrm{HCl}$ to a product solution of $1 \mathrm{M} \mathrm{HClO}_{4}$, whereas about $25 \%$ of the $\mathrm{Pt}(\mathrm{IV})$ and Pd(II) was transported during the same period. Considerable differences in the transport rates were observed with such low TOA concentrations between $\mathrm{Au}(\mathrm{III})$ and both $\mathrm{Pt}(\mathrm{IV})$ and $\mathrm{Pd}(\mathrm{II})$; this may thus provide a feasible transport process for the separation of $\mathrm{Au}(\mathrm{III})$ from others.

Since the extraction power of TOA for $\mathrm{Pt}(\mathrm{IV})$ and $\mathrm{Pd}(\mathrm{II})$ is appreciably lower than that for $\mathrm{Au}(\mathrm{III})$, higher concentrations of TOA are required for the transport of $\mathrm{Pt}(\mathrm{IV})$ and $\mathrm{Pd}(\mathrm{II})$. Figure 4 illustrates the transport behavior of precious metals across an SLM with such a moderate TOA concentration as $0.03 \mathrm{M}$. The decreasing rate in the feed side and the increasing rate in the product side were accelerated compared with the case of a low TOA concentration. An anomalous slowing down in the transport rates of $\mathrm{Pt}(\mathrm{IV})$ and $\mathrm{Pd}(\mathrm{II})$ was observed during the period of $60-120 \mathrm{~min}$; this may be attributable to the fact that TOA in the SLM was preferentially used for the transport of Au(III). More than $90 \%$ of $\mathrm{Au}(\mathrm{III})$ and $95 \%$ of $\mathrm{Pt}(\mathrm{IV})$ and $\mathrm{Pd}(\mathrm{II})$ were simultaneously recovered into the product solution after the transport had lasted for $7 \mathrm{~h}$.

The transport behavior of precious metals at such high concentrations of TOA as $0.5 \mathrm{M}$ is represented in Fig. 5 . The fractions of all the metals in the feed solution decreased in a similar manner. The fractions in the product solution smoothly increased for $\mathrm{Pt}(\mathrm{IV})$ and Pd(II), whereas the fraction of Au(III) was considerably lower compared with that expected from the decreasing profile of the feed side. A high TOA concentration brought about a serious third phase containing $\mathrm{Au}$ (III) species in the product side of the SLM, in which about $60 \%$ of $\mathrm{Au}$ (III) remained in the SLM. In this case, most of the accumulated $\mathrm{Au}$ (III) could be recovered by rinsing the SLM with ethanol after the experiments.

The fractions of metals remaining in the feed solution

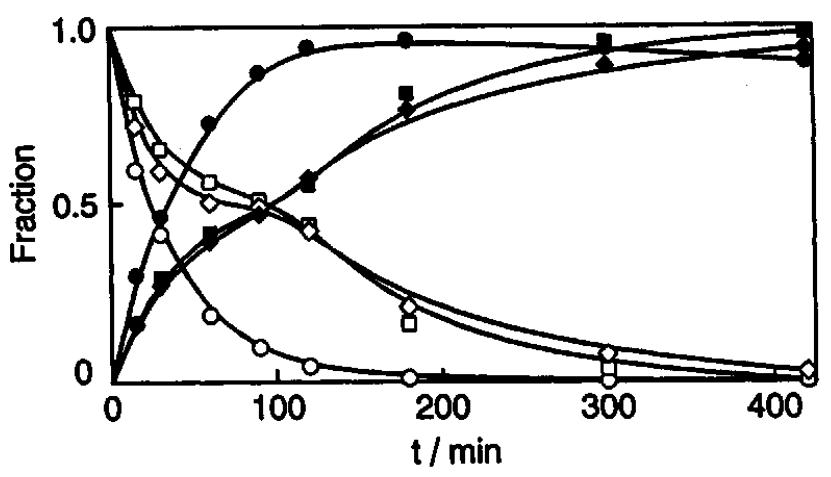

Fig. 4 Transport of precious metals through an SLM containing $0.03 \mathrm{M}$ TOA and 20\%(v/v) 1-octanol. Feed, 0.1 M $\mathrm{HCl}$; product, $1 \mathrm{M} \mathrm{HClO}_{4}$. $\mathrm{Au}(\mathrm{III})(\mathrm{O}, \bullet), \operatorname{Pt}(\mathrm{IV})(\diamond, \diamond)$, $\operatorname{Pd}(\mathrm{II})(\square, \square)$. Open, feed; closed, product.

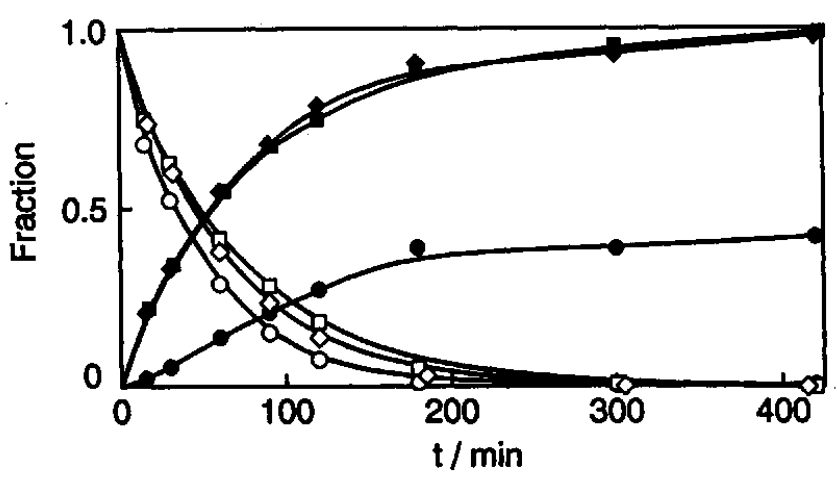

Fig. 5 Transport of precious metals through an SLM containing $0.5 \mathrm{M}$ TOA and $20 \%(\mathrm{v} / \mathrm{v})$ 1-octanol. Feed, $0.1 \mathrm{M}$ $\mathrm{HCl}$; product, $1 \mathrm{M} \mathrm{HClO}_{4}$. $\mathrm{Au}(\mathrm{III})(\mathrm{O}, \bullet), \mathrm{Pt}(\mathrm{IV})(\diamond, \diamond)$, $\operatorname{Pd}(\mathrm{II})(\square, \square)$. Open, feed; closed, product.

at the end of the experiment for $7 \mathrm{~h}$ are shown in Fig. 6 as a function of the carrier concentration. All of the $\mathrm{Au}(\mathrm{III})$ was removed from the feed solution regardless of the TOA concentration in the SLM, while the fractions of $\mathrm{Pt}(\mathrm{IV})$ and $\mathrm{Pd}(\mathrm{II})$ decreased along with the TOA concentration below $0.03 \mathrm{M}$; above this level these two metals were also completely removed from the feed solution.

The recovery of metals in the product side during the experiments is shown in Fig. 7 as a function of the TOA concentration. Gold(III) was efficiently transported across an SLM containing a TOA below $0.01 \mathrm{M}$, and almost quantitatively recovered in the product solution. However, the $\mathrm{Au}$ (III) recovery gradually decreased along with an increase in the TOA concentration, due to an insufficient stripping ability on the product side. On the contrary, the recoveries of $\mathrm{Pt}(\mathrm{IV})$ and $\mathrm{Pd}(\mathrm{II})$ increased along with the TOA concentration up to $0.05 \mathrm{M}$; above this level they were quantitative during the same period. 


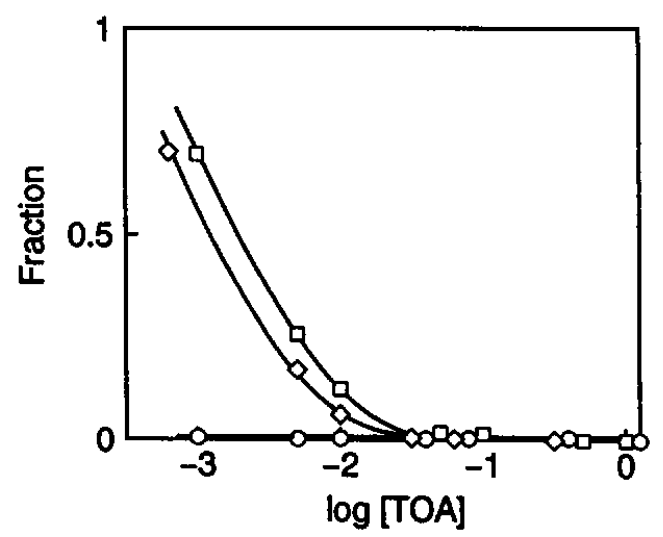

Fig. 6 Effect of the TOA concentration on the precious-metal fractions in the feed solution at $7 \mathrm{~h} . \quad \operatorname{Au}(\mathrm{III})(\mathrm{O}), \operatorname{Pt}(\mathrm{IV})(\diamond)$, $\operatorname{Pd}(\mathrm{II})(\square)$.

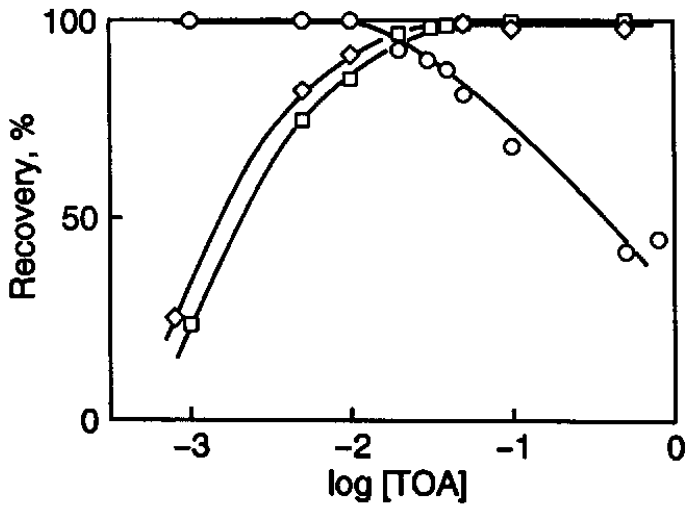

Fig. 7 Effect of the TOA concentration on the recovery of precious metals in the product solution at $7 \mathrm{~h}$. $\mathrm{Au}(\mathrm{III})(\mathrm{O})$, $\operatorname{Pt}(\mathrm{IV})(\diamond), \operatorname{Pd}(\mathrm{II})(\square)$.

\section{Separation of $\mathrm{Au}(I I I)$ from $\mathrm{Pt}(\mathrm{IV})$ and $\mathrm{Pd}(\mathrm{II})$}

In order to optimize the separation conditions of $\mathrm{Au}(\mathrm{III})$ from $\mathrm{Pt}(\mathrm{IV})$ and $\mathrm{Pd}(\mathrm{II})$, the separation parameters were determined at different acid concentrations in the feed and product solutions.

The decreasing rates of metals in the feed solution are expressed by

$$
\ln \left([\mathrm{M}]_{\mathrm{f}, \mathrm{t}} /[\mathrm{M}]_{\mathrm{f}, 0}\right)=-k_{\mathrm{f}, \mathrm{obs}} t
$$

where $[M]_{f, t}$ and $[M]_{\mathrm{r}, 0}$ denote, respectively, the concentrations of the metal species at time $t$ and zero in the feed solution, and $k_{\mathrm{f}, \mathrm{obs}}\left(\mathrm{s}^{-1}\right)$ is the apparent rate constant. Since the fractions for the feed and product sides yielded approximately symmetrical fraction curves, except for the high region of the TOA concentration, the $k_{\mathrm{f}, \mathrm{obs}}$ value can be regarded as being the apparent rate constant for the overall transport of the desired metal species.

Table 1 presents the transport parameters across an SLM containing $10^{-3} \mathrm{M}$ TOA at different $\mathrm{HCl}$ concentrations in the feed solution. The values of $k_{\mathrm{f}, \mathrm{obs}}$ for $\mathrm{Au}(\mathrm{III})$ were considerably larger than those for $\mathrm{Pt}(\mathrm{IV})$ and $\mathrm{Pd}(\mathrm{II})$. The $\mathrm{HCl}$ concentration in the feed solution had a large influence on the transport rates of $\mathrm{Pt}(\mathrm{IV})$ and $\mathrm{Pd}(\mathrm{II})$; at a relatively higher concentration of $\mathrm{HCl}$ the transport of $\mathrm{Pt}(\mathrm{IV})$ and $\mathrm{Pd}(\mathrm{II})$ became practically negligible, while the $k_{\mathrm{f}, \mathrm{obs}}$ value of $\mathrm{Au}(\mathrm{III})$ only slightly declined.

The separation factor $(\alpha)$ is given by the ratio of the $k_{\mathrm{f}, \text { obs }}$ values of two metals. The $\alpha$ values for $\mathrm{Au}(\mathrm{III})$ to $\mathrm{Pt}(\mathrm{IV})$ and $\mathrm{Pd}(\mathrm{II})$ were firmly enhanced with increasing $\mathrm{HCl}$ concentration from 0.1 to $4.0 \mathrm{M}$, and a high $\alpha$ value of over 250 was obtained at $4.0 \mathrm{M} \mathrm{HCl}$.

The results on the transport behavior at different $\mathrm{HClO}_{4}$ concentrations in the product solution are also listed in Table 1. The variation in the $\mathrm{HClO}_{4}$ concentration from 0.1 to $4.0 \mathrm{M}$ exerted a weak effect on the separation parameters; the $\alpha$ value was reduced at high $\mathrm{HClO}_{4}$ concentrations. On the other hand, low $\mathrm{HClO}_{4}$ concentrations resulted in a lowering of the recovery due to insufficient stripping on the product side of the SLM.

As can be seen in Fig. 8, under optimum conditions, more than $95 \%$ of the initial $\mathrm{Au}(\mathrm{III})$ was selectively recovered in the product solution, leaving about $99 \%$ $\mathrm{Pt}(\mathrm{IV})$ and $\mathrm{Pd}(\mathrm{II})$ in the $4 \mathrm{M} \mathrm{HCl}$ feed solution after $7 \mathrm{~h}$.

In conclusion, the separation of $\mathrm{Au}(\mathrm{III})$ from $\mathrm{Pt}(\mathrm{IV})$

Table 1 Effect of the acid concentration on the separation factor and recovery

\begin{tabular}{|c|c|c|c|c|c|c|c|c|c|}
\hline \multirow{2}{*}[\mathrm{HCl}]{$_{\mathrm{f}} / \mathrm{M}$} & \multirow{2}{*}[\mathrm{HClO}_{4}]{$_{\mathrm{p}} / \mathrm{M}$} & \multicolumn{3}{|c|}{$k_{\mathrm{f}, \mathrm{obs}} / \mathrm{s}^{-1}$} & \multicolumn{2}{|c|}{ Separation factor } & \multicolumn{3}{|c|}{ Recovery at $7 \mathrm{~h}, \%$} \\
\hline & & $\mathrm{Au}$ & $\mathbf{P t}$ & $\mathbf{P d}$ & $\alpha_{\mathrm{Au} / \mathrm{Pt}}$ & $\alpha_{\mathrm{Au} / \mathbf{P d}}$ & $\mathrm{Au}$ & $\mathbf{P t}$ & $\mathrm{Pd}$ \\
\hline 0.1 & 1.0 & $2.74 \times 10^{-4}$ & $1.73 \times 10^{-5}$ & $1.66 \times 10^{-5}$ & 15.8 & 16.5 & 100 & 25.5 & 23.9 \\
\hline 0.4 & & $2.65 \times 10^{-4}$ & $1.12 \times 10^{-5}$ & $8.40 \times 10^{-6}$ & 23.7 & 31.5 & 99.5 & 29.4 & 25.7 \\
\hline 0.7 & & $2.46 \times 10^{-4}$ & $4.20 \times 10^{-5}$ & $3.30 \times 10^{-6}$ & 58.6 & 74.5 & 99.8 & 17.4 & 17.9 \\
\hline 1.0 & & $2.06 \times 10^{-4}$ & $2.80 \times 10^{-6}$ & $1.90 \times 10^{-6}$ & 73.6 & 108.4 & 96.7 & 1.3 & 2.6 \\
\hline 4.0 & & $1.77 \times 10^{-4}$ & $6.60 \times 10^{-7}$ & $5.20 \times 10^{-7}$ & 268.2 & 340.4 & 95.7 & 1.1 & 1.0 \\
\hline \multirow[t]{3}{*}{0.1} & 0.1 & $1.30 \times 10^{-4}$ & $6.70 \times 10^{-6}$ & $5.50 \times 10^{-6}$ & 19.4 & 23.6 & 88.7 & 12.9 & 12.3 \\
\hline & 2.0 & $2.28 \times 10^{-4}$ & $2.08 \times 10^{-5}$ & $1.64 \times 10^{-5}$ & 10.9 & 13.9 & 99.1 & 35.2 & 31.9 \\
\hline & 4.0 & $1.63 \times 10^{-4}$ & $1.75 \times 10^{-5}$ & $1.23 \times 10^{-5}$ & 9.3 & 13.3 & 97.4 & 26.7 & 21.2 \\
\hline
\end{tabular}

SLM: $10^{-3} \mathrm{M}$ TOA and $20 \%(\mathrm{v} / \mathrm{v}) 1$-octanol in kerosene; $\alpha_{\mathrm{M} 1 / \mathrm{M} 2}=k_{\mathrm{f}, \mathrm{obs}(\mathrm{M} 1)} / k_{\mathrm{f}, \mathrm{obs}(\mathrm{M} 2) \text {. }}$ 


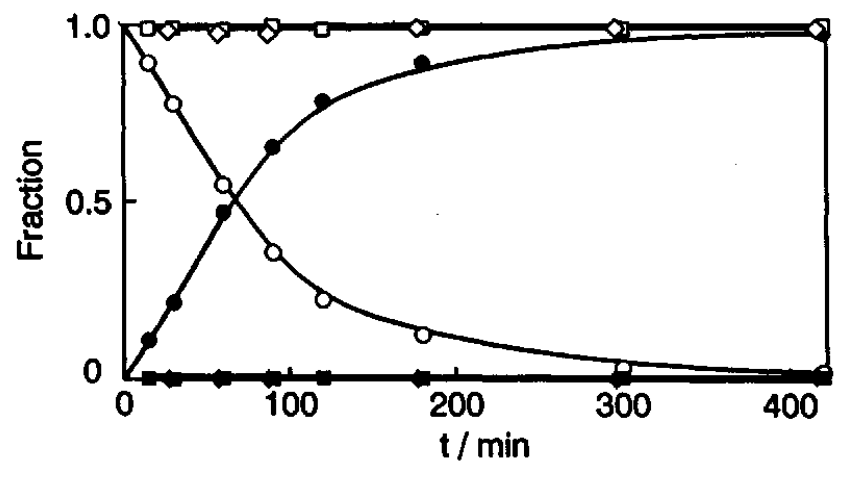

Fig. 8 Transport of precious metals from a high $\mathrm{HCl}$ feed solution. SLM, $10^{-3} \mathrm{M}$ TOA and $20 \%$ (v/v) 1-octanol in kerosene; feed, $4 \mathrm{M} \mathrm{HCl}$; product, $1 \mathrm{M} \mathrm{HClO}_{4}$. $\operatorname{Au}(\mathrm{III})(O, \ominus), \operatorname{Pt}(\mathrm{IV})(\diamond, \diamond), \operatorname{Pd}(\mathrm{II})(\square, \square) . \quad$ Open, feed; closed, product.

and $\mathrm{Pd}(\mathrm{II})$ was accomplished through the SLM impregnated with TOA as a mobile carrier. Gold(III) was selectively transported from the $4 \mathrm{M} \mathrm{HCl}$ feed solution containing Pt(IV) and Pd(II) across the SLM with a low concentration of TOA. The simultaneous recovery of these metals was performed at a limited moderate concentration region of TOA. At a high TOA concentration, $\mathrm{Pt}(\mathrm{IV})$ and $\mathrm{Pd}(\mathrm{II})$ were recovered on the product side, remaining the large portion of $\mathrm{Au}(\mathrm{III})$ in the SLM.

\section{References}

1. R. Bloch, in "Membrane Science and Technology", ed. J. E. Flin, p. 177, Plenum, New York, London, 1970.

2. P. R. Danesi, Sep. Sci. Technol., 19, 857 (1984-85).

3. R. W. Baker, M. E. Tuttle, D. J. Kelly and H. K. Lonsdale, J. Membrane Sci., 2, 213 (1977).

4. O. Loiacono, E. Drioli and R. Molinari, J. Membrane Sci., 28, 123 (1986).

5. P. R. Danesi and C. Cianetti, J. Membrane Sci., 20, 201 (1984).

6. P. R. Danesi, J. Membrane Sci., 14, 161 (1983).

7. L. M. Gindin, in "Ion Exchange and Solvent Extraction", ed. J. A. Marinsky and Y. Marcus, p. 311, Marcel Dekker, Inc., New York and Basel, 1981.

8. E. Anticō, M. Hidalgo, A. Masana, V. Salvadō, M. Munõz and M. Valiente, in "Solvent Extraction 1990", ed. T. Sekine, p. 1505, Elsevier, Amsterdam, London, New York, Tokyo, 1992.

9. J. Fu, S. Nakamura and K. Akiba, Sep. Sci. Technol., 30, 609 (1995).

10. J. Fu, S. Nakamura and K. Akiba, Sep. Sci. Technol., 30, 793 (1995).

11. J. Fu, S. Nakamura and K. Akiba, Anal. Sci., 10, 935 (1994).

12. K. Akiba and T. Kanno, Sep. Sci. Technol., 18, 831 (1983).

13. M. J. Cleare, P. Charlesworth and D. J. Bryson, J. Chem. Tech. Biotechnol., 29, 210 (1979).

(Received September 26, 1994) (Accepted November 24, 1994) 